\title{
Perancangan Sistem Informasi Ujian Online Berbasis Website pada SD Integral Hidayatullah Depok
}

\author{
Sanjaya ${ }^{1}$, Yosef Kristian Wongkar ${ }^{2}$, Ardi Taryanto ${ }^{3}$ \\ 1,2,3Politeknik Piksi Ganesha Indonesia \\ e-mail: ${ }^{1}$ sanjaya.piksi.18302052@gmail.com, ${ }^{2}$ yosefkristian95@gmail.com, \\ 3ardipiksi@yahoo.com
}

\begin{abstract}
Abstrak
Ujian ialah salah satu pendekatan yang bertujuan untuk proses evaluasi pembelajaran yang direncanakan untuk mengukur tingkat pencapaian siswa sebagai pelajar sehingga pendidik dan pelajar dapat mengetahui tingkat kemampuanya.Tujuan mendasar dari penelitian ini ialah membuat sistem informasi ujian online berbasis website menggungakan Framework Codeigniter dan database MySQL pada SD Integral Hidayatullah Depok. Metode penelitian yang dipakai ialah metode kualitatif deskritif untuk mencari fakta dan informasi asli. Teknik pengumpulan informasi yang digunakan ialah dengan menggunakan pengamatan (observasi), wawancara (intervieuw), dan studi literatur, sesuai dengan topik masalah, sedangkan metode pengembangan yang digunakan yaitu metode waterfall. Ujian yang berjalan di Sekoalah Dasar Integral Hidayatullah Depok pada awalnya masih menggunakan teknik tradisional, khususnya tes dilakukan secara langsung dan personal di ruang kelas dengan lembar soal dan jawaban yang dicetak oleh pihak sekolah. Merebaknya kasus Covid-19 menjadi titik awal permasalahan tatanan kehidupan mayarakat, termasuk dampaknya terhadap sistem pendidikan di Indonesia, dampak dari semua ini mengharuskan aktivitas belajar dilakukan secara online, salah satunya adalah sistem ujian. Untuk mengatasi masalah terkait penulis memberi saran dan menarik kesimpulan untuk mengembangkan sebuah program Sistem Informasi Ujian Online berbasis website menggunakan Framework Codeigniter dan database MySQL di SD Integral Hidayatullah Depok, yang mana bisa digunakan untuk mendukung ujian secara online.
\end{abstract}

Keywords: Sistem Informasi, Ujian Online, Framework, MySQL

\begin{abstract}
The examination is one approach that aims to evaluate the learning process there had planned to measure the degree of students achievement as students so that educators and students can find out their level of ability. The fundamental objective of this research is to design a webbased online exam information system using the Codelgniter Framework and MySQL database at the Hidayatullah Integral Elementary School Depok. The research method uses descriptive qualitative methods to find facts and original information. The information collection technique used is by using observation, interviews, and literature study, according to the topic of the issue, whereas the development method used is the waterfall method. The exams running at the Hidayatullah Integral Elementary School in Depok were initially still using traditional techniques, especially the tests were carried out directly and personally in the classroom with the question and answer sheets printed by the school. The outbreak of the Covid-19 case has become a starting point of problems with the order for people's lives, including the impact on the education system in Indonesia. The effect requires that learning activities have held online, one of which is the exam system. To overcome the problems related to the writer gives suggestions and conclude to develop a website-based Online Exam Information System program using the Codelgniter Framework and MySQL database at the Hidayatullah Integral Elementary School Depok, which can be used is to support online exams
\end{abstract}

Keywords: Informasi System, Online exam, Framework, MySQL 


\section{Pendahuluan}

Ujian ialah salah satu pendekatan yang bertujuan untuk proses evaluasi pembelajaran. Di dalam pendidikan, ujian direncanakan untuk mengukur tingkat pencapaian siswa sebagai pelajar, sehingga pendidik dan pelajar dapat mengetahui tingkat kemampuannya dalam memahami bidang studi. Ujian juga media untuk memperkirakan kapasitas, karakter, dan wawasan siswa dalam bidang studi yang di pelajari, dengan hasil estimasi tersebut maka dapat penilaian yang dimanfaatkan untuk menerima pilihan yang berbeda. (Susilowati \& Hidayat, 2018).

Menurut Basuki dan Hariyanto (2015 : 22) ujian ialah alat penilaian atau metode penilaian yang efisien, legal, serta tepat sasaran untuk menentukan kopetensi, kemampuan dan tingkat informasi siswa tentang materi yang ditampilkan, sebagai tugas atau masalah yang harus di tangani siswa atau sekelompok siswa.(Basuki, 2015)

Pandemi Covid-19 saat ini menjadi kejadian luar biasa di seluruh dunia, di tahun terakhir ini proses penyebarannya terjadi begitu cepat. Di Indonesia kecepatan penyebaran penyakit dapat dilihat dari peningkatan kasus perharinya. Menyebabkan sistem pendidikan di seluruh dunia tidak berjalan seperti yang diharapkan. Secara tidak langsung, sistem informasi dan teknologi komputer diminta untuk dikembangkan sesuai dengan tingkat kebutuhan. Peningkatan sistem informasi saat ini harus dijalankan dengan tepat untuk sebuah lembaga pendidikan seperti SD Integral Hidayatullah Depok. (Haryono, 2021).

SD Integral Hidayatullah sendiri merupakan salah satu organisasi edukatif. Perancangan yang ditampilkan di Sekolah Dasar Integral Hidayatullah merupakan kerangka pesantren Modern, yang mengkonsolidasikan keseluruhan mata pelajaran Layanan Pendidikan dan Kebudayaan dan mata pelajaran luar biasa atau diniyah.

Ujian yang berjalan di SD Integral Hidayatullah Depok pada awalnya masih menggunakan teknik tradisional, khususnya tes dilakukan secara langsung dan personal diruang kelas dengan lembar soal dan jawaban yang dicetak oleh pihak sekolah dan nilai di periksa manual oleh pengajar. $\begin{array}{ccc}\text { Merebaknya kasus } & \text { Covid-19 } \\ \text { menjadi titik tolak masalah terhadap }\end{array}$ tatanan kehidupan masyarakat, termasuk berdampak pada sistem pendidikan di Indonesia. Salah satunya Sekolah Dasar Integral Hidayatullah yang terdampak pandemi Covid-19 yang mengharuskan aktivitas belajar dilakukan secara online, salah satunya adalah sistem ujian. Untuk meminimalisir resiko penuluran yang sangat luas, SD Integral Hidayatullah membutuhkan kerangka kerja agar sistem pendidikan bisa tetap berjalan. (Haryono, 2021).

Dalam hal ini Peneliti tertarik untuk mengembangkan sistem informasi ujian online berbasis website. Tujuan penelitian ini adalah merancang sebuah program Perancangan Sistem Informasi Ujian Online berbasis website menggunakan Framework Codeigniter dan database MySQL di SD Integral Hidayatullah Depok yang bisa digunakan untuk mendukung ujian secara online dan mampu mengatasi masalah yang ada saat ini. (Hidayat, 2020).

\section{Metode Penelitian}

Dalam melengkapi kebutuhan dan memperoleh informasi guna mendukung penelitian, metode yang digunakan antara lain:

1. Pengumpulan Data

a) Observasi

Melakukan pengamatan di SD Integral Hidayatullah saat berjalanya ujian sebagai rancangan pemahaman yang digunakan untuk panduan dalam membuat komposisi website ini.

b) Wawancara

Mengadakan diskusi secara online kepada pihak terkait yaitu Tata Usaha yang ditunjuk sebagai sumber memperoleh data kebutuhan untuk sistem ujian.

c) Studi Literatur

Mengumpulkan informasi berdasar jurnal dan pemeriksaan terkait untuk mendapatkan referensi tentang teknik dan tahap perkembangan yang tepat.

\section{Metode Waterfall}

Metode waterfall merupakan sebuah kerangka atau strategi peningkatan pemograman yang digunakan peneliti. Teknik ini sendiri memiliki beberapa tahapan sebagai berikut: 
a) Analisis Sistem

Menganalisis kebutuhan sistem sebagai prasyarat untuk diusulkan dan mengetahui jenis program yang dibutuhkan.

b) Desain

Tahap mengolah informasi yang telah dipecah menjadi bentuk agar dapat di pahami oleh pengguna.

c) Pembuatan Kode Program

Menyusun kode program yang telah dibuat menjadi jenis perintah yang dipahami komputer menggunakan bahasa pemograman untuk pengembangan suatu sistem.

d) Pengujian

Tahap pengujian dilakukan untuk menjamin bahwa kerangka yang dibuat adalah sesuai rencana dan semua dapat di manfaatkan secara tepat tanpa kesalahan.

e) Pemeliharaan (Maintenance)

Tahap terakhir. Sistem yang telah selesai kemudian dijalankan dan selanjutnya dilakukan pemeliharaan untuk menemukan bebagai macam kesalahan yang ditemukan pada sebelumya.

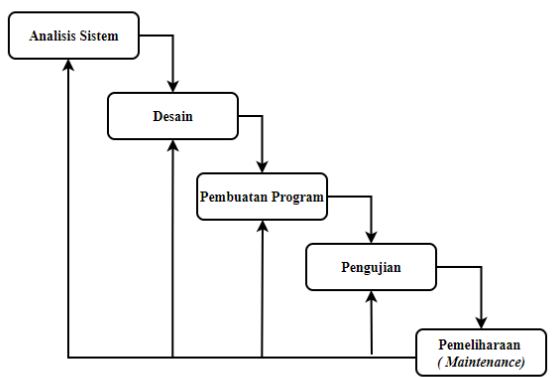

Gambar 1: Alur Waterfall

(Sukamto, R. A., dan Shalahudin, 2014)

\section{Hasil dan Pembahasan}

Dari metode penelitian yang dirujuk di atas diketahui, memperoleh hasil analisis yang berjalan di SD Integral Hidayatullah Depok saat ini, sebagai berikut:

\subsection{Analisa Kebutuhan}

Sistem berjalan siswa saat ujian manual.

a) Siswa membayar biaya ujian, melunasi pembayaran total melalui TU. Apabila belum membayar tidak bisa mendapatkan kartu ujian.

b) Siswa mendapatkan kartu ujian

c) Siswa mengerjakan soal ujian

d) Siswa mengumpulkan ujian

\section{e) Siswa mendapatkan Nilai}

Dari uraian analisis ujian yang berlajan pada Sekolah Dasar Integral Hidayatullah Depok dapat dinyatakan dalam Use Case Diagram sebagai berikut:

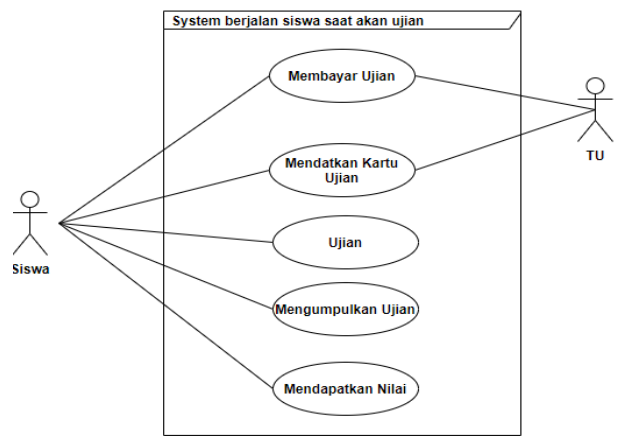

Gambar 2: Use Case sistem berjalan siswa ujian

Sistem Berjalan Guru.

a) Membuat soal Perguru Mata pelajaran

b) Acc Kepala Sekolah

c) Soal di ujikan.

d) Penilaian hasil ujian

e) Nilai

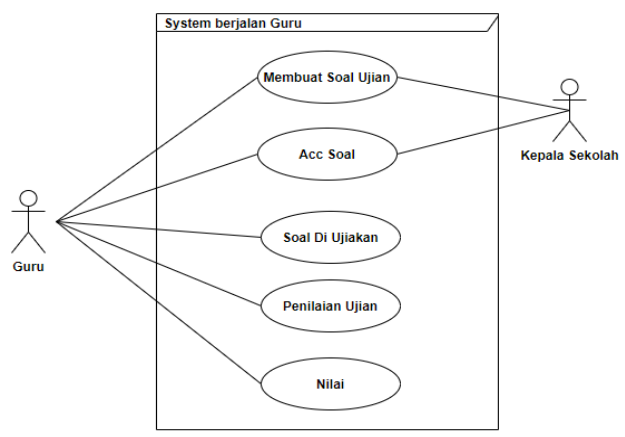

Gambar 3: Use Case sistem berjalan Guru

\subsection{Analisa sistem usulan.}

Setelah menganalisa masalah tersebut, maka diperlukan suatu sitem yang dapat membantu proses ujian online. Oleh karena itu, produk ini direncanakan dapat diandalkan untuk dapat mengatasi masalah tersebut. Berikut susunan yang dibuat:

\section{A. Use Case Diagram}

a) Halaman Siswa

Siswa sebagai pelaku yang masuk terlebih dahulu, untuk bisa mengikuti ujian secara online melalui situs tersebut. Model 
proses ditunjukan pada Gambar 4 .

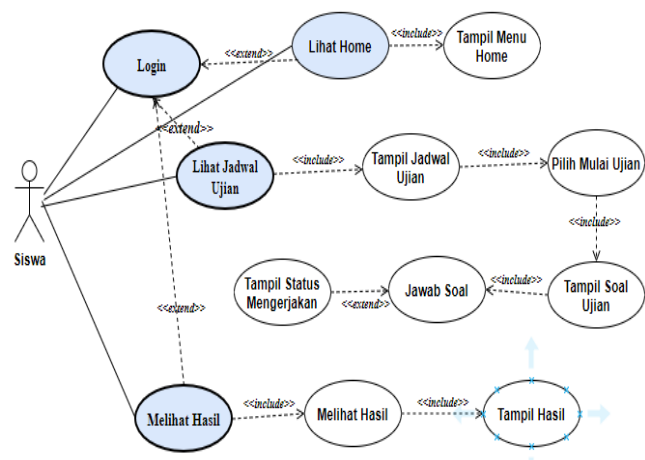

Gambar 4. Use Case Halaman Siswa

b) Halaman Guru

Guru Sebagai pelaku yang masuk dan mengelola soal, kelola peserta dan melihat hasil ujian dan bisa mencetak nilai siswa. Model proses ditunjukan pada Gambar 5.

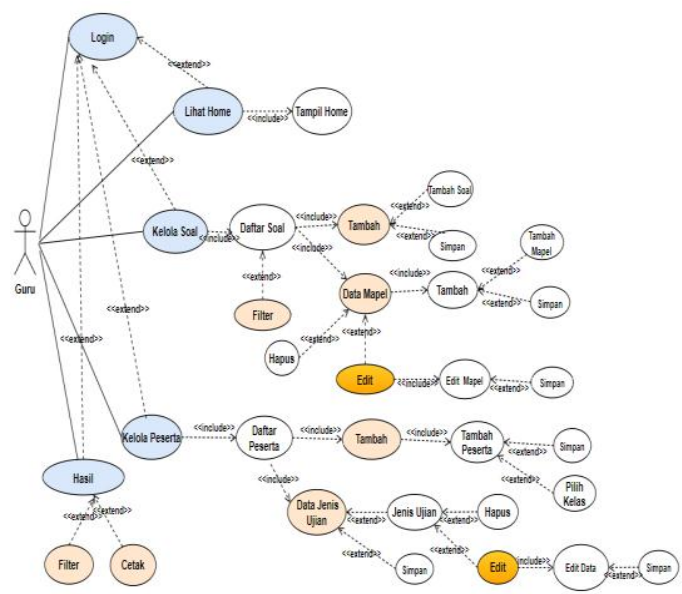

Gambar 5. Use Case Halaman Guru

c) Halaman Admin

Admin sebagai pelaku yang masuk dan memiliki hak akses lengkap untuk data mencakup data guru, data siswa, kelola soal, kelola peserta dan melihat hasil. Model proses ditunjukan pada Gambar 6 .

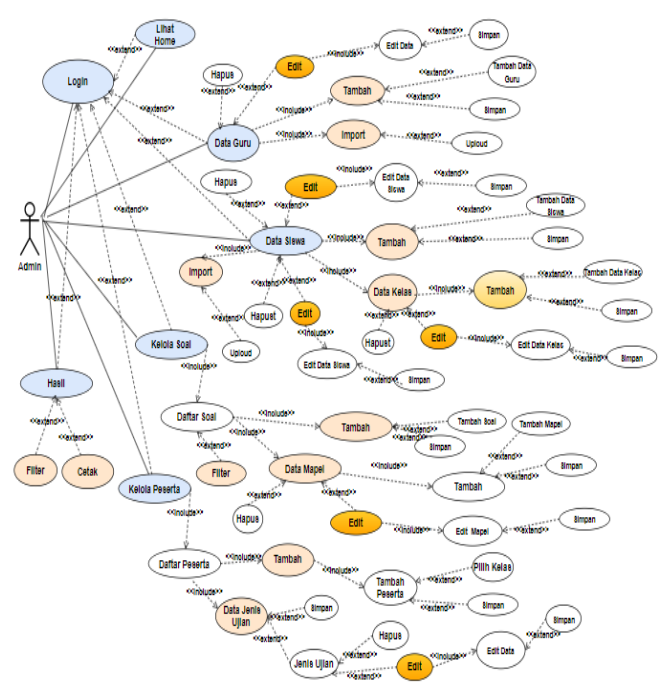

Gambar 6. Use Case halaman admin (Riyadi et al., 2019).

\section{B. Activity Diagram}

a) Siswa melakukan ujian

Siswa melakukan kegiatan sebagai pelaku pada sistem, masuk dan memilih ujian yang diambil dan mengisi jawaban. Proses kegiatan ditunjukan pada Gambar 7.

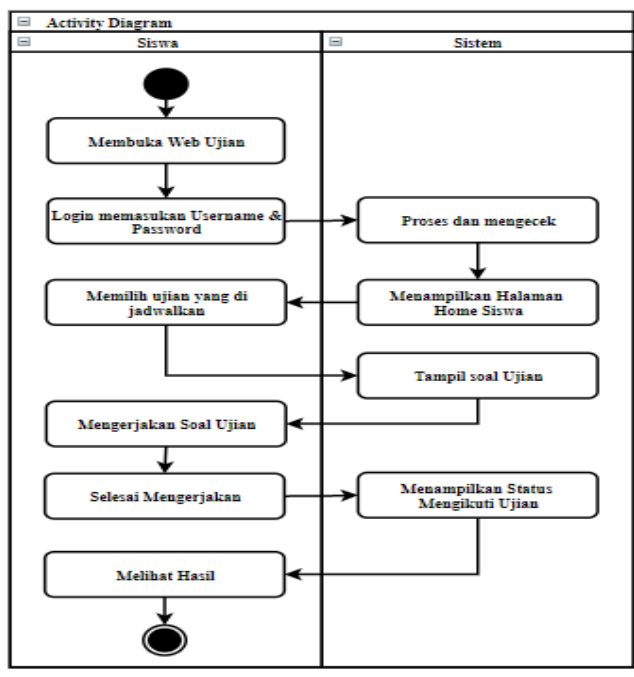

Gambar 7. Activity Diagram Siswa mengerjakan ujian

b) Guru Kelola soal

Guru Melakukan kegiatan sebagai pelaku pada sistem, masuk dan memilih kelola soal. Proses kegiatan ditunjukan pada gambar 8. 


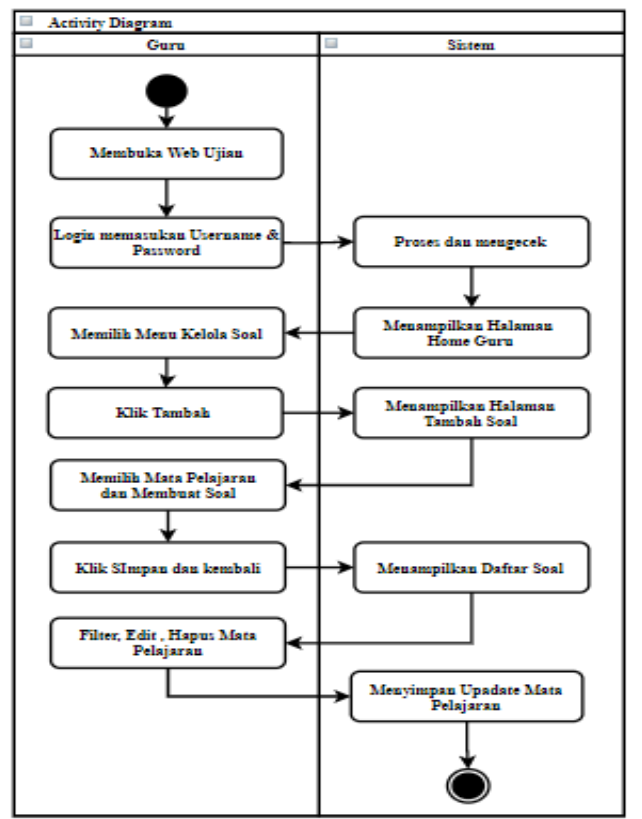

Gambar 8. Activity Diagram Guru Kelola Soal

c) Guru Kelola peserta ujian

Guru Melakukan kegiatan sebagai pelaku pada sistem, masuk dan memilih kelola peserta. Proses kegiatan ditunjukan pada gambar 9 .

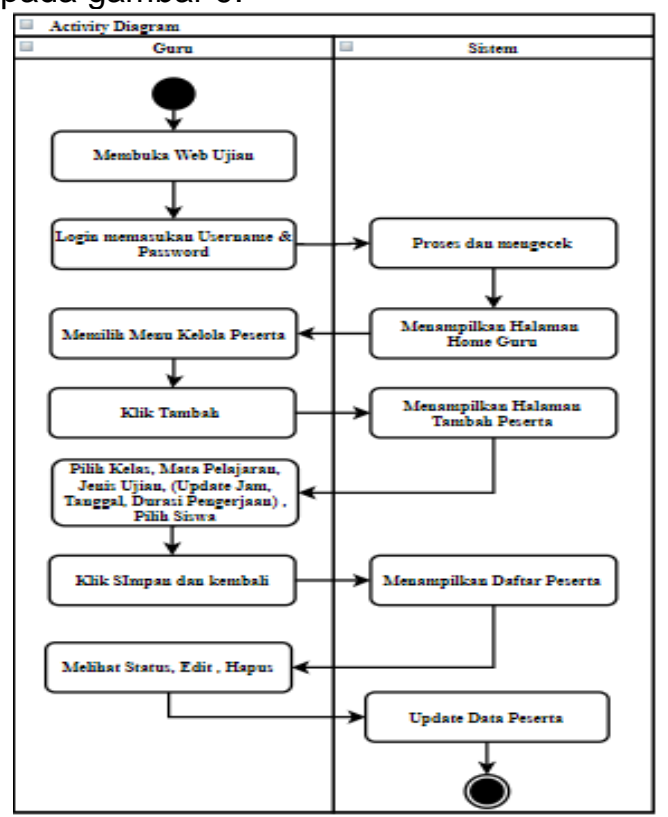

Gambar 9. Activity Diagram Guru Kelola peserta

d) Guru Memeriksa hasil dan cetak nilai

Guru Melakukan kegiatan sebagai pelaku pada sistem, masuk dan memilih hasil. Proses kegiatan ditunjukan pada gambar 10.

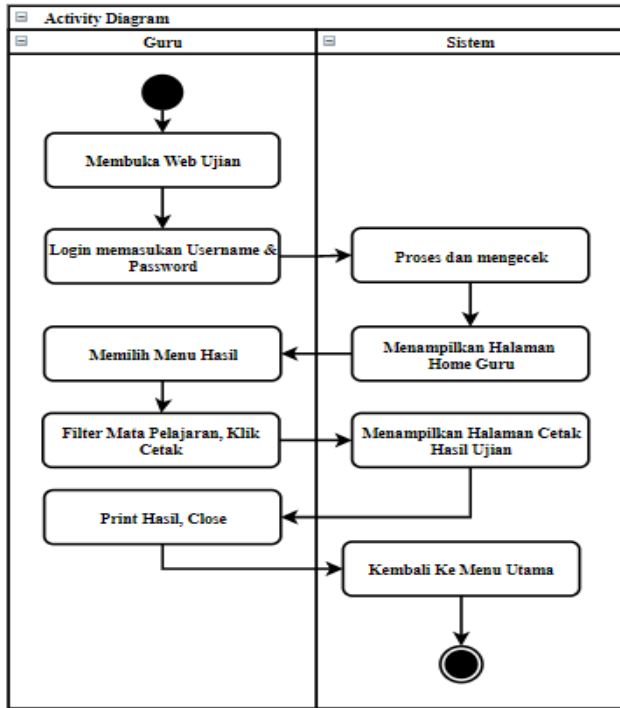

Gambar 10. Activity Diagram Guru Memeriksa hasil

e) Admin mengakses data dan kelola soal, peserta dan hasil

Admin bisa mengakses semua kegitan. Proses kegiatan ditunjukan pada gambar 11.

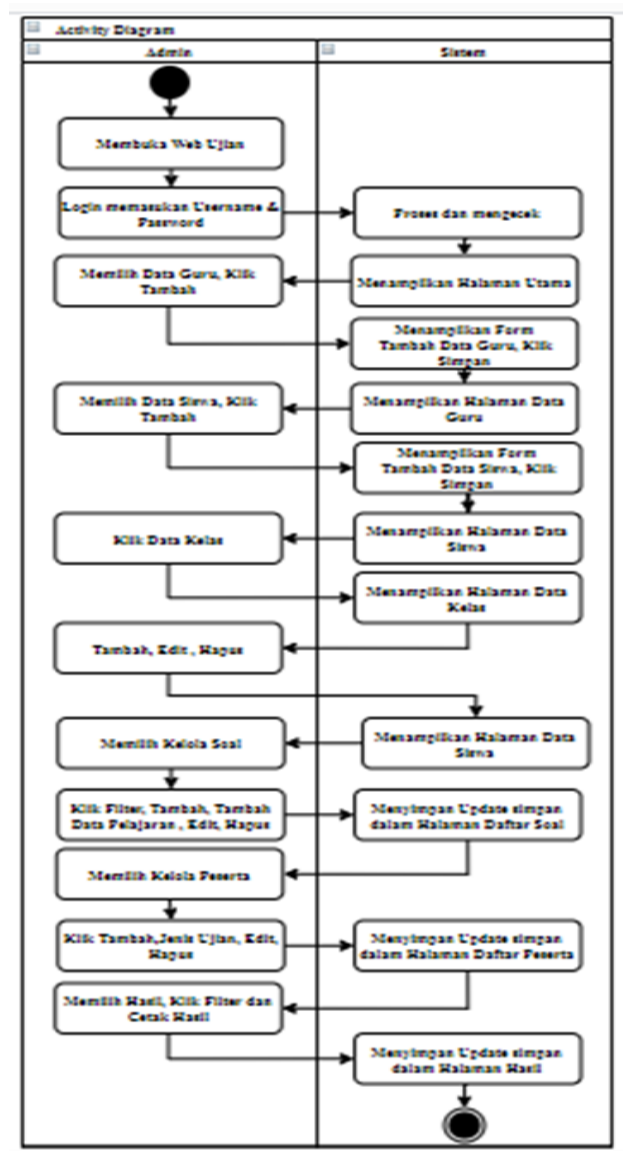

Gambar 11. Activity Diagram Admin akses semua kegiatan 


\subsection{Desain}

Tahapan ini membahas tentang desain database dan desain user interface pada sistem yang dibuat.

1. Database

Perancangan basis data menggunakan ERD (Entity Relationship Diagram) dan LRS (Logical Record Structure). Hubungan entititas yang didesain dapat dilihat pada gambar berikut:

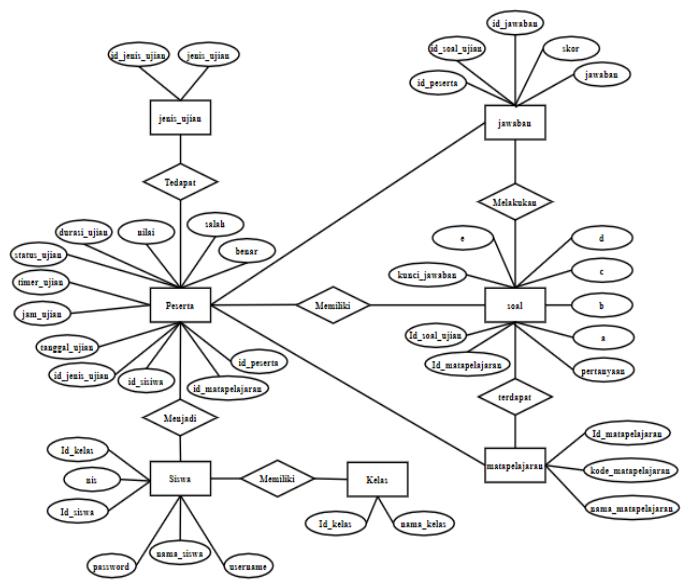

Gambar 12. Entity relationship diagram

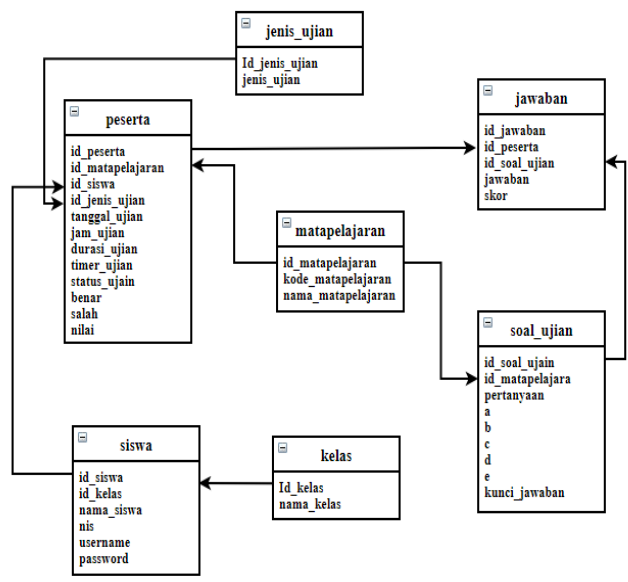

Gambar 13. Logical Record Structure

Spesifikasi yang digunakan pada program diusulkan

a) Processor Intel Core i5 @ $2.00 \mathrm{GHz}$

b) Ram Minimal 4 GB

c) Hardisk Minimal $256 \mathrm{~GB}$

d) Resolusi layar $1366 \times 768$

e) Keyboard dan Mouse

f) Printer

Perangkat pendukung berjalanya aplikasi Ujian online ialah

a) Windows 10 yang digunakan untuk pengembangan, pelaksanaan dan pemakaian

b) Bahasa Pemograman Menggunakan PHP c) Framework yang digunakan adalah Codeigneiter versi 3

d) Perancangan tampilan menggunakan Bootstrap v3.4.1

e) XAMPP Version: 5.6.31 untuk database

f) Membuat diagram menggunakan situs online https://app.diagrams.net/

(Tisnawati \& Prabowo, 2020)

\section{User Interface}

Implementasi perancangan interface terbagi menjadi 3 yakni Pelaksanaan perancangan interface Siswa, Guru dan admin

a. Halaman Login

Halaman ini diisi sebagai menu login. Penyajianya dapat dilihat pada Gambar13.

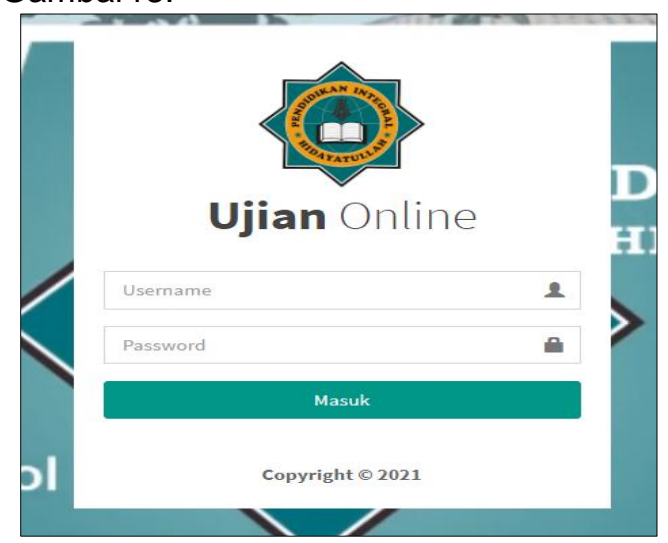

Gambar 13. Tampilan Login

b. Halaman Siswa

Halaman ini diisi sebagai halaman siswa untuk mengetahui jadwal ujian serta memulai ujian dan hasil pengerjaan ujian. Tampilanya seperti gambar berikut:

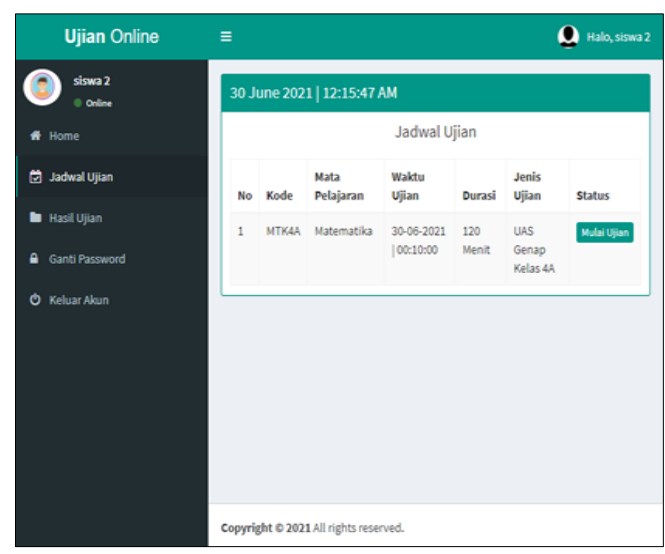

Gambar 14. Jadwal Ujian Siswa 


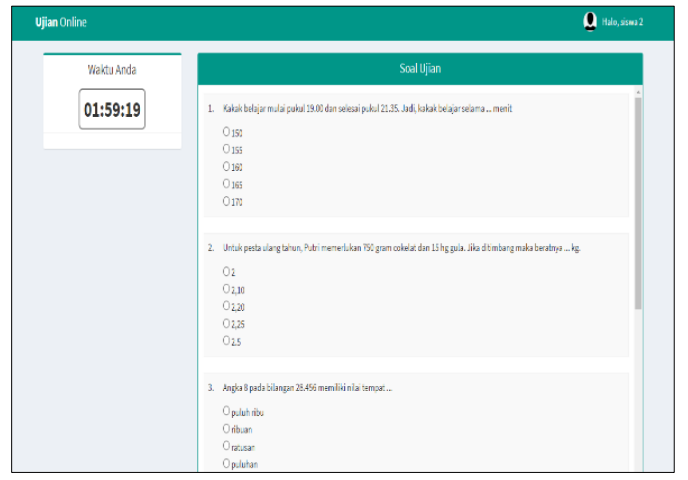

Gambar 15. Memulai Ujian

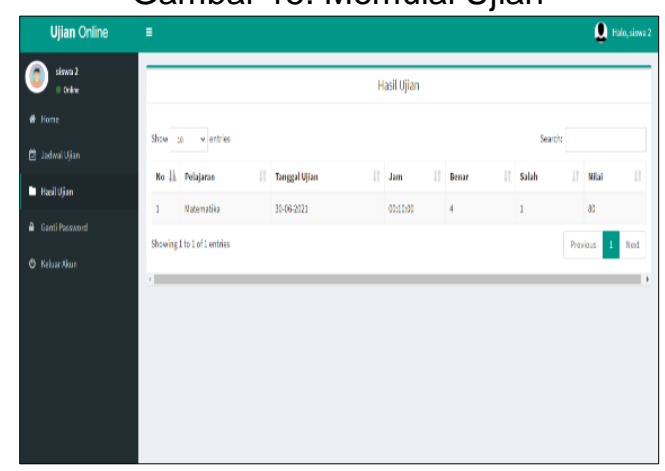

Gambar 16. Hasil Ujian

d. Halaman Guru.

Halaman ini diisi sebagai hakaman guru untuk melakukan kelola peserta ujian, kelola soal ujian dan hasil ujian. Tampilan seperti pada gambar berikut:

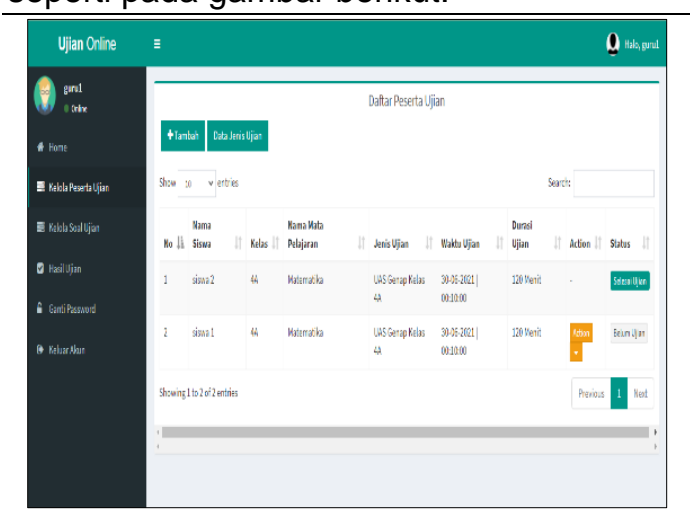

Gambar 17. Halaman Kelola Peserta

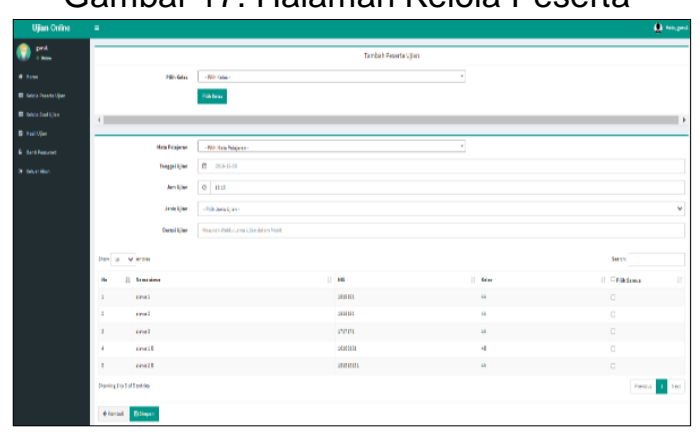

Gambar 18. Halaman Kelola Tambah Peserta
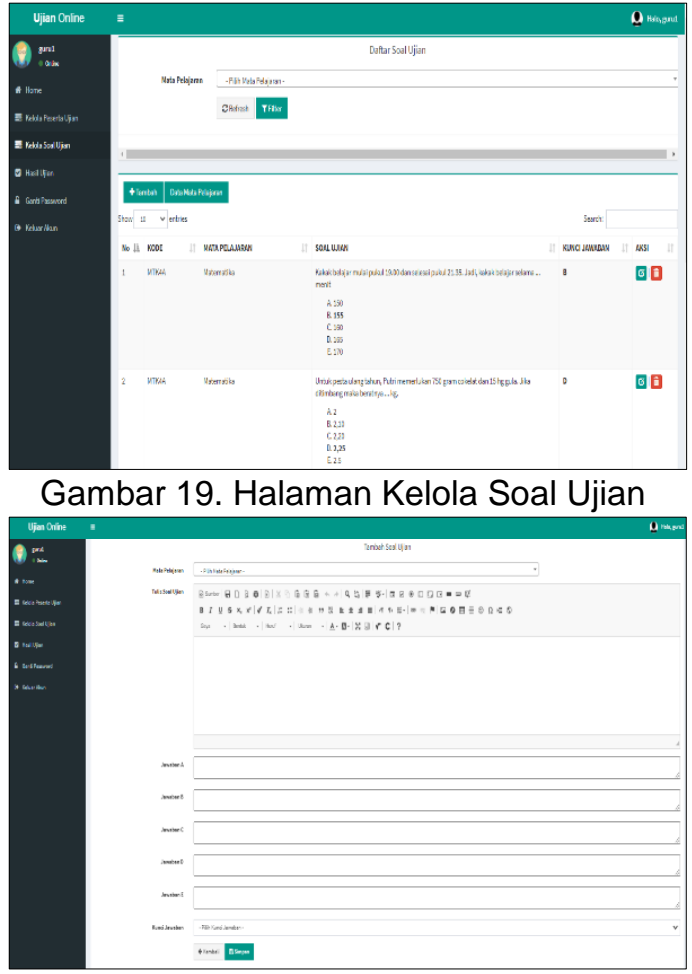

Gambar 20. Halaman Tambah Soal Ujian

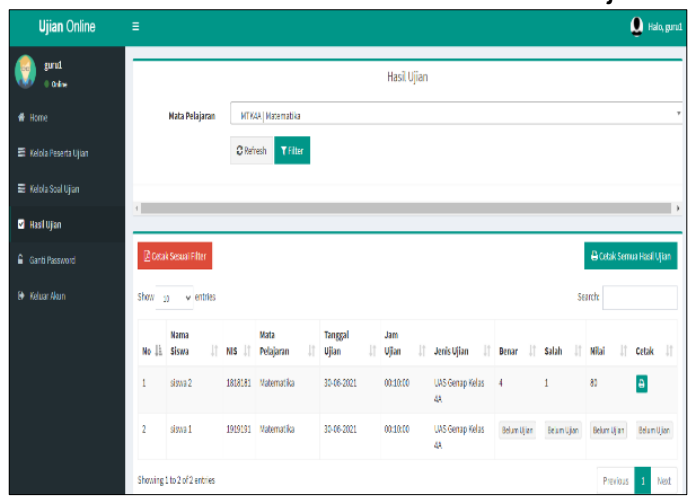

Gambar 21. Hasil Ujian

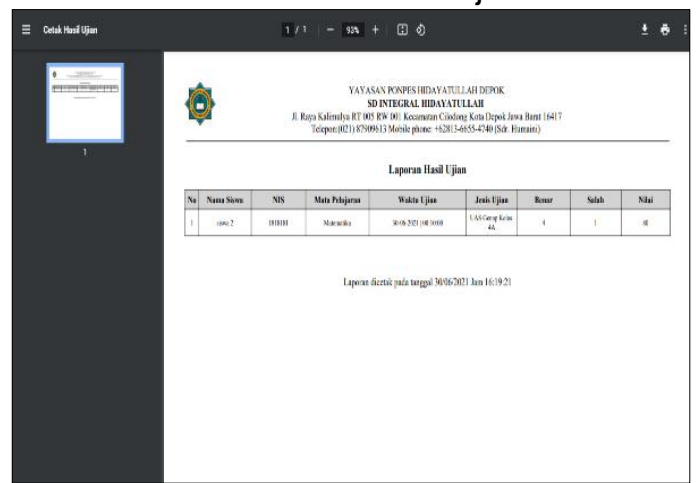

Gambar 22. Cetak Hasil Ujian 


\subsection{Kesimpulan}

Diharapkan dengan adanya perancangan sistem informasi Ujian Online ini di percaya dapat membantu SD Integral Hidayatullah Depok dalam menangani masalah tersebut. Sehingga dapat disimpulkan bahwa:

a. Aplikasi Ujian Online ini dapat membantu mengatasi masalah bagi sekolah dalam meningkatkan kecukupan serta pengawasan nilai secara online dengan internet.

b. Mengurangi biaya cetak dan lembar jawaban dan memudahkan siswa dan guru untuk melihat hasil nilai secara online.

c. Aplikasi ini memiliki beberapa keunggulan dibandingkan dengan sistem secara manual, dimana proses ujian lebih cepat dan efektif karena tidak memerlukan media bahan tulis, membatasi kecurangan dalam interaksi ujian dan siswa tidak perlu menunggu lama untuk mengetahui hasil mereka yang muncul secara berurutan.

\subsection{Saran}

Dari kesimpulan yang telah dikemukakan, disarankan untuk kemajuan maka perlu dikembangkan aplikasi di kemudian hari, yaitu:

a. Aplikasi ini hanya untuk sekolah dasar dan dibutuhkan pengembangan agar dapat berjalan di berbagai tahapan seperti anroid dan IOS dan bisa dikembangkan jenjang sekolah yang lain.

b. Peningkatan penampilan dan layout

c. Peningkatan pada jenis pertanyaan yang di ujikan.

\section{Daftar Pusta}

Basuki, I. (2015). Asesmen Pembelajaran. PT Remaja Rosdakarya.

Haryono, R. A. dan W. (2021). Rancang Bangun Simulasi Ujian Online Berbasis Web Pada Smk Satria. Journal of Artificial Intelligence and Innovative Applications, 1(1), 51-59.

Hidayat, A. (2020). Aplikasi Sistem Informasi Akademik SD Integral Hidayatullah Depok Berbasis Java. Jurnal Fasilkom, 10(3), 290-296. https://doi.org/10.37859/jf.v10i3.2281

Riyadi, A., Hermaliani, E. H., \& Utami, D. Y. (2019). Pembuatan Aplikasi Sistem Ujian Online Pada Smk Garuda
Nusantara Bekasi. Jurnal Ilmiah

SINUS, 17(1), 23.

https://doi.org/10.30646/sinus.v17i1.3 83

Sukamto, R. A., dan Shalahudin, M. (2014). Rekayasa Perangkat Lunak Terstruktur dan Berorientasi Objek. Bandung: Informatika Bandung.

Susilowati, S., \& Hidayat, T. (2018). Rancang Bangun Sistem Informasi Ujian Online (Studi Kasus Pada SMAN 58 Jakarta). Jurnal Teknik Komputer, 4(1), 30-36. http://bsnpindonesia.org

Tisnawati, R., \& Prabowo, B. T. A. P. (2020). Menggunakan Microsoft Visual Studio 2010 Dan Database Mysql Di Cv. Gaya Baru Motor Bandung. 8, 70-81. 